\title{
Estratégias para produção de mudas de tomateiro utilizando paclobutrazol
}

\section{Strategies for tomato seedlings production using paclobutrazol}

\author{
Alexsander Seleguini ${ }^{*}$; Max José de Araujo Faria Júnior²; \\ Katiane Santiago Silva Benett ${ }^{3}$; Odair Lacerda Lemos ${ }^{4}$; Shizuo Seno ${ }^{5}$
}

\section{Resumo}

\begin{abstract}
A tomaticultura moderna, de mesa ou para processamento industrial, demanda mudas de qualidade, capazes de resistir às adversidades ambientais após o plantio e que mantenham o padrão produtivo do genótipo. O objetivo deste trabalho foi avaliar o efeito de três concentrações de $\operatorname{PBZ}\left(0,50\right.$ e $\left.100 \mathrm{mg} \mathrm{L}^{-1}\right)$ e dois métodos de aplicação (tratamento de sementes e rega de plântulas) na emergência de plântulas e produção de mudas de tomateiro de crescimento indeterminado. Adotou-se o delineamento inteiramente casualizado, em esquema fatorial $2 \times 3$, com quatro repetições. Foi avaliada a emergência de plântulas, o índice de velocidade de emergência, altura de plântulas e diâmetro do caulículo e suas respectivas taxas de crescimento absoluto (TCA), área foliar, massa de matéria seca da parte aérea, das raízes e total, e razão de área foliar (RAF). Os dados foram submetidos a analise de variância e as médias dos níveis do fator "métodos de aplicação" comparadas pelo teste de Tukey, a 5\% e as médias dos níveis do fator "concentrações" submetidas à análise de regressão. A aplicação de paclobutrazol via rega de plântulas não comprometeu a emergência de plântulas, reduziu significativamente a taxa de crescimento das plântulas e, conseqüentemente, o porte das mudas, sem afetar o diâmetro do caulículo, além de permitir acúmulo de matéria seca de raízes. A concentração de $50 \mathrm{mg} \mathrm{L}^{-1}$ mostrou-se suficiente para obtenção de plântulas mais compactas, sem prejuízo à área foliar, na aplicação via rega, além de permitir um incremento de cerca de $37 \%$ na massa de matéria seca de raízes.
\end{abstract}

Palavras-chave: Solanum lycopersicum L., triazol, regulador de crescimento, estiolamento de mudas

\begin{abstract}
The modern tomato production, either for fruit table production or for processing, has required quality seedlings, able to withstand environmental adversities after planting and maintaining the standard genotype productive. The aim of this study was to evaluate the effect of three concentrations of PBZ $(0,50$ and $100 \mathrm{mg} \mathrm{L}-1)$ and two methods of application (seed treatment and watering seedlings) on seedling emergence and seedling production of tomato growth indeterminate. We adopted a completely randomized in a $2 \times 3$ factorial scheme with four replications. We evaluated the seedling emergence, the rate of speed of emergence, seedling height and diameter of hypocotyl and their absolute growth rate (TCA), leaf area, dry weight of shoots, roots and total, and reason leaf area (RAF). Results were subjected to analysis of variance and the mean levels of the factor "methods of application" compared
\end{abstract}

1 Prof. Dr. do Setor de Horticultura, Escola de Agronomia, Universidade Federal de Goiás, UFG, Goiânia, GO. E-mail: aseleguini@ gmail.com

2 Prof. Dr. do Dept $^{\circ}$ de Apoio a Produção e Saúde Animal, Faculdade de Medicina Veterinária, UNESP, Araçatuba, SP. E-mail: maxfaria@fmva.unesp.br

3 Prof $^{\mathrm{a}} \mathrm{Dr}^{\mathrm{a}}$. do Dept ${ }^{\mathrm{o}}$ de Agronomia, Unidade Universitária de Ipameri, UEG, Ipameri, GO. E-mail: kasantiago@ig.com.br

4 Prof. Dr. do Dept ${ }^{\circ}$ Engenharia Agrícola e Solos, UESB, Vitória da Conquista, BA. E-mail: E-mail: odairlacerda@hotmail.com

5 Prof. Dr. do Dept ${ }^{\mathrm{o}}$ Fitotecnia, Tecnologia de Alimentos e Sócio Economia, Faculdade de Engenharia, Ilha Solteira, SP. E-mail: shizuo@agr.feis.unesp.brotmail.com

Autor para correspondência 
by Tukey test at $5 \%$ and the mean levels of the factor "concentrations" subjected to regression analysis. The application of paclobutrazol via seedlings watering did not affect seedling emergence, significantly reduced the rate of seedling growth and, consequently, the size of the seedlings without affecting the diameter of hypocotyl, plus allow accumulation of dry roots. A concentration of $50 \mathrm{mg} \mathrm{L}-1$ was shown to be sufficient to obtain seedlings more compact, subject to leaf area, the application via watering, beyond allowing an increase of about $37 \%$ in dry weight of roots.

Key words: Solanum lycopersicum L., triazole, growth regulator, seedling etiolation

\section{Introdução}

A regularidade de oferta de hortaliças ao longo do ano é um dos principais desafios atuais da olericultura. Para tanto, novos sistemas de produção estão sendo empregados, como os cultivos em ambiente protegido, hidropônico e em substrato. Face à complexidade crescente desses sistemas de produção, a etapa referente à produção de mudas tende a ser feita por produtores especializados, que atuam como fornecedores de mudas para aqueles dedicados à produção final (NICOLA; BASOCU, 2000). No Brasil, horticultores especializados nessa atividade estão surgindo em vários Estados e demandando informações quanto à produção e manejo de mudas de diferentes espécies hortícolas (ANDRIOLO; BOEMO; BONINI, 2001).

Um dos problemas comumente observados na produção de mudas é o rápido desenvolvimento da parte aérea, que pode provocar estiolamento, com formação de mudas alongadas, frágeis e com poucas raízes (NASCIMENTO; SALVALAGIO; SILVA, 2003). Além disso, plantas estioladas tendem a ser menos resistentes aos estresses ambientais ou a determinadas doenças, principalmente por ocasião do transplantio. Uma das práticas utilizadas em outros países é o condicionamento do crescimento, com estimulação química ou física, ou estresse suave aplicado às mudas, visando regular o crescimento e a qualidade das mudas (LATIMER, 1991). Além de regular o crescimento das plântulas, $\mathrm{o}$ condicionamento aumenta a resistência das mesmas a estresses ambientais, bem como a determinadas doenças (BOVI; MINAMI, 1999).

O condicionamento químico consiste no emprego de reguladores de crescimento, aplicados às mudas via pulverização foliar ou rega, métodos, estes, que propiciam eficiente controle do crescimento. Porém, as desvantagens da aplicação de reguladores de crescimento, via rega do substrato ou foliar, referem-se, respectivamente, às perdas de produto pela adsorção do solo ou do substrato e pela deriva, o que eleva os custos e diminui a segurança da aplicação. Ainda, tanto a aplicação no solo (ou substrato) como a foliar podem requerer o uso de soluções altamente concentradas de reguladores de crescimento, o que pode conduzir ao acúmulo de resíduos nas culturas. Tais resíduos acumulados são perigosos à saúde humana, fato que pode restringir o uso dos reguladores em plantas (DAVIS; STEFFENS; SANKHLA, 1988).

Segundo Fletcher et al. (2000), o tratamento de sementes em pré-semeadura é um caminho alternativo de aplicação de reguladores de crescimento às plantas, e vêm sendo aprimorado e adaptado a várias espécies vegetais. Implica na embebição da semente em solução contendo o regulador por tempo determinado, dependendo de sua tolerância, seguido por um período de secagem à temperatura ambiente. Entretanto, alguns efeitos indesejáveis podem ser mencionados, os quais incluem a redução e o atraso da emergência de plântulas (PILL; GUNTER, 2001).

O paclobutrazol (PBZ) pertence a classe dos reguladores de crescimento e ao grupo dos inibidores de biossíntese de giberelinas (RADEMACHER, 2000). Essa inibição consiste no bloqueio da atividade das enzimas monooxigenases P450 no retículo endoplasmático que impedem a formação de GA12-aldeído, primeira giberelina ativa no metabolismo vegetal e precursora de todas as outras (KENDE; ZEEVAART, 1997). Consequentemente, há a redução dos níveis de todas as formas livres de 
ácido giberélico (SYMONS, 1989; FLETCHER et al., 2000).

As monooxigenases P450 participam de inúmeras rotas metabólicas, portanto a sua inibição resulta em vários efeitos secundários. Verifica-se o aumento nos teores de citocinina, ácido abscisico e auxina e, diminuição dos níveis de etileno (FLETCHER et al., 2000). Além disso, propicia uma maior resistência a estresses bióticos e abióticos devido a maior eficiência na regulação da absorção dos íons $\mathrm{K}^{+}, \mathrm{Na}^{+}, \mathrm{Ca}^{2+}$ e Cl-(HAJIHASHEMI et al., 2007; SHARMA et al., 2011), menor degradação de clorofila (STILL; PILL, 2004; BANINASAB; GHOBADI, 2011), redução de fotoinibição (BANINASAB; GHOBADI, 2011) e aumento nos teores de prolina, superóxido dismutase, catalase e peroxidase (SHARMA et al., 2011; BANINASAB; GHOBADI, 2011). Seleguini et al. (2011) observaram alterações tecnológicas de pós-colheita (perda de matéria fresca e firmeza) de tomates oriundos de plântulas tratadas com paclobutrazol.

O tratamento de sementes com PBZ foi efetivo no controle da altura de mudas de calêndula, gerânio e tomate (PASIAN; BENNETT, 2001; PILL; GÜNTER, 2001; NASCIMENTO; SALVALAGIO; SILVA, 2003). Vários estudos, no entanto, têm indicado desvantagens do tratamento de sementes com PBZ, que incluem demora e redução na emergência da muda (GIOVINAZZO; SOUZAMACHADO, 2001; PASIAN; BENNETT, 2001).

Face ao exposto e considerando a carência de informações, principalmente no Brasil, quanto ao emprego do PBZ na produção de mudas, foi objetivo deste trabalho, avaliar o efeito de métodos e concentrações de PBZ na emergência, desenvolvimento e qualidade de mudas de tomateiro de crescimento indeterminado.

\section{Material e Métodos}

O experimento foi desenvolvido na Fazenda de Ensino, Pesquisa e Extensão da Faculdade de Engenharia - UNESP, no município de Ilha Solteira-SP, em abrigo para cultivo protegido com orientação leste-oeste, teto em forma de arco, coberto com filme de polietileno transparente de $75 \mu \mathrm{m}$ de espessura e tela de sombreamento de 50\%.

Estudaram-se os efeitos de três concentrações de $\operatorname{PBZ}\left(0,50\right.$ e $\left.100 \mathrm{mg} \mathrm{L}^{-1}\right)$ e dois métodos de aplicação (tratamento de sementes e rega de plântulas) na emergência de plântulas e produção de mudas de tomateiro híbrido AF 7631, de crescimento indeterminado, tipo longa vida.

Nos tratamentos referentes à aplicação de PBZ às sementes utilizou-se as concentrações de 0,50 e 100 $\mathrm{mg} \mathrm{L} \mathrm{L}^{-1}$ para umedecer o substrato papel filtro. Após este procedimento as sementes foram distribuídas entre o papel filtro papel e acondicionadas em caixa tipo gerbox, sob temperatura de $25^{\circ} \mathrm{C}$, por 24 horas. Depois de embebidas, as sementes foram secas à temperatura ambiente, em papel de filtro, por uma hora.

Adotou-se o delineamento inteiramente casualizado, em esquema fatorial $2 \mathrm{X} 3$, com quatro repetições. As parcelas foram dispostas em bandejas de poliestireno expandido com 200 células, sendo que cada bandeja comportou três parcelas com 40 células cada. As posições das bandejas na bancada foram periodicamente alteradas. A semeadura foi realizada em substrato comercial Plantimax ${ }^{\circledR}$, colocando-se uma semente por célula, sendo as mesmas cobertas com o próprio substrato. Nas parcelas correspondentes aos tratamentos em que o PBZ foi aplicado via rega, procedeu-se à aspersão de $5 \mathrm{~mL}$ de solução, por plântula, nas concentrações de regulador de crescimento pertinentes a cada tratamento, aos 15 dias após a semeadura, sendo este volume suficiente para um bom molhamento das folhas e do substrato.

As soluções de paclobutrazol utilizadas foram preparadas a partir do produto comercial contendo $15 \%$ do ingrediente ativo $(\mathrm{m} / \mathrm{m})$. Inicialmente, foi preparada uma solução padrão a $1 \%$, diluindo-se 6,66 g do produto comercial em $100 \mathrm{~mL}$ de álcool 
e, na sequência, para obtenção das concentrações desejadas de 50 e $100 \mathrm{mg} \mathrm{L}^{-1}$ foram feitas diluições desta solução padrão em água destilada.

As mudas foram irrigadas com PBZ três vezes ao dia (às 9, 13 e 17 horas) e além disto receberam fertirrigação com solução completa de macro e micronutrientes e adubação nitrogenada $(0,3 \%$ de uréia), irrigando-se as mudas com regador e, logo em seguida, com água.

$\mathrm{Na}$ primeira etapa, para verificar o efeito do tratamento das sementes com o PBZ, a emergência foi avaliada a cada dois dias, do $5^{\circ}$ ao $15^{\circ}$ dia após a semeadura, para fins do cálculo do índice de velocidade de emergência, sendo utilizada a fórmula descrita por Maguirre (1962). Na segunda etapa, para avaliar o efeito dos métodos e das concentrações de PBZ no crescimento e qualidade das mudas, foram avaliadas, as seguintes variáveis: a) altura de plântulas, aos 30 dias após a semeadura; b) taxa de crescimento absoluto (TCA) para altura de plantas, entre o $15^{\circ}$ e $30^{\circ}$ dia após a semeadura, (BENINCASA, 1988); c) diâmetro do caulículo, medido na base; d) área foliar (determinada com o uso de um scanner de mesa, da marca Genius, modelo ColorPage Vivid-Pro II e o software Image Tool); e) massa de matéria seca da parte aérea, das raízes e total e; g) razão de área foliar (RAF), conforme Benincasa (1988), que corresponde à relação entre área foliar (área responsável pela interceptação de energia luminosa e $\mathrm{CO}_{2}$ ) e a matéria seca total (resultado da fotossíntese).

Os dados foram submetidos a analise de variância e as médias dos níveis do fator "métodos de aplicação" comparadas pelo teste de Tukey a 5\% de probabilidade e as médias dos níveis do fator "concentrações" submetidas à análise de regressão polinomial.

\section{Resultados e Discussão}

A emergência de plântulas (\%) decresceu linearmente com o incremento na concentração de paclobutrazol (PBZ) aplicado nas sementes, em avaliações realizadas aos 7, 11 e 15 dias após a semeadura, (Figura 1A). Enquanto que o índice de velocidade de emergência (IVE), relativo ao período compreendido entre o $5^{\circ}$ e $15^{\circ}$ dia após a semeadura, apresentou comportamento quadrático, assumindo valor mínimo $(9,18)$ na concentração de $100 \mathrm{mg} \mathrm{L}^{-1}$ (Figura 1 B). Estes resultados foram semelhantes àqueles obtidos por Mäge e Powell (1990), que verificaram inibição na germinação de sementes de maçã tratadas com PBZ, bem como aos de Pasian e Bennett (2001), que constataram que a germinação de sementes de tomate, gerânio e cravo-de-defunto, em laboratório, foi reduzida com o aumento nas concentrações de PBZ.

De acordo com Pill e Gunter (2001) e Pasian e Bennett (2001), o efeito inibitório da embebição de sementes em soluções contendo PBZ pode estar associado à sua penetração nas mesmas, causando toxicidade ao embrião, com redução nos níveis de GA a valores insuficientes para a germinação e para o crescimento da plântula. Segundo Hung, Fritz e Waters (1992), o aumento das concentrações e dos tempos de exposição das sementes ao regulador de crescimento contribuiu para a elevação na taxa de penetração do produto nas sementes e conseqüente redução da germinação. 
Figura 1. Emergência de plântulas (A), em percentagem, aos 7, 11 e 15 dias após a semeadura, e índice de velocidade de emergência (B), estimado entre $05^{\circ}$ e $15^{\circ}$ dia após a semeadura, em função da concentração de paclobutrazol, para sementes de tomateiro AF 7631, tratadas por embebição por 24 horas. Ilha Solteira (SP), 2007.

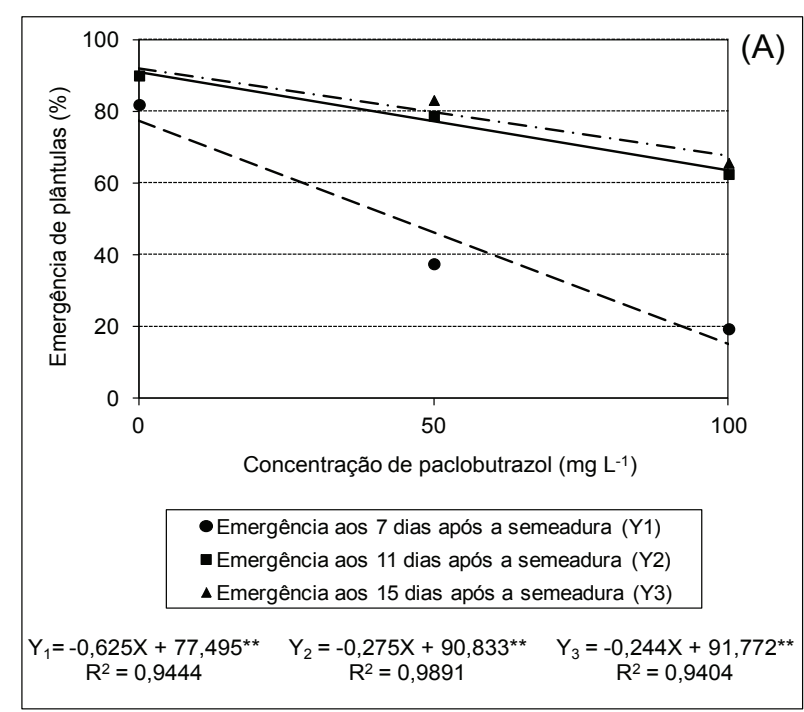

** - regressão polinomial significativa $(\mathrm{P}<0,01)$

Fonte: Elaboração dos autores.

Assim, no $15^{\circ}$ dia após a semeadura, foi constatado que $83 \%$ e $65 \%$ das sementes tratadas, respectivamente, com 50 e $100 \mathrm{mg} \mathrm{L}^{-1}$ de PBZ, originaram plântulas normais, enquanto no tratamento testemunha (embebição em água), estes valores ultrapassaram 90\% (Figura 1). A perda de $35 \%$ das sementes, após a embebição por 24 horas em $100 \mathrm{mg} \mathrm{L}^{-1}$ de PBZ, pode comprometer o emprego comercial deste tratamento, principalmente, quando se utilizam sementes melhoradas de alto custo de aquisição, como no caso de híbridos de tomateiro longa-vida. Segundo Barbosa; Costa; Sá (2011) a produção de hortaliças como o tomate deve ser estabelecido com o uso de sementes com alto padrão de germinação.

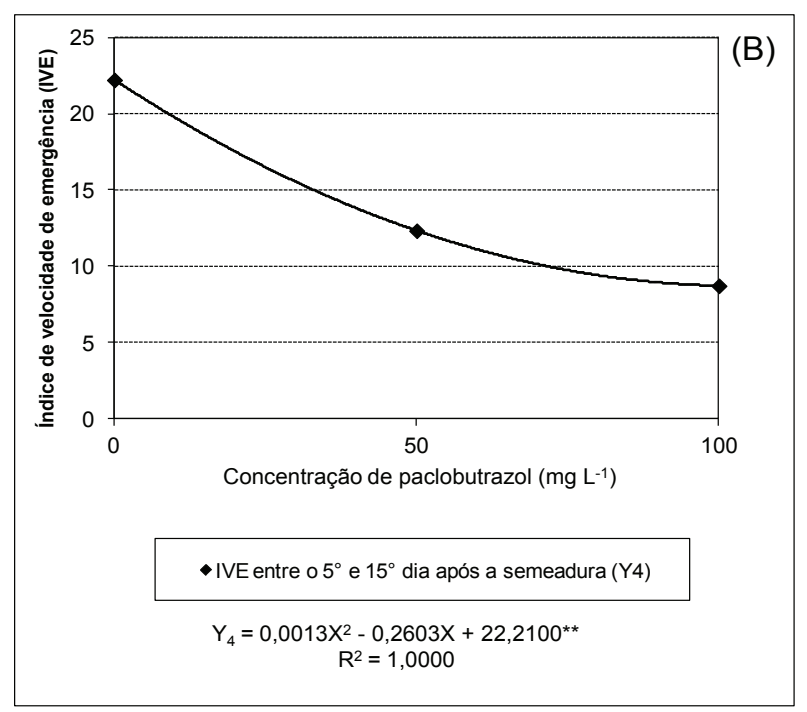

Não foi detectada interação significativa entre os métodos de aplicação e as concentrações de PBZ para altura de plântulas, aos 30 dias após a semeadura, entretanto houve efeito significativo das concentrações de PBZ, sem que fossem observadas diferenças entre os métodos de aplicação do regulador de crescimento (Tabela 1 ).

A da altura de plântulas, oriundas de sementes tratadas com PBZ, seguiu um ajuste quadrático com o aumento da concentração do regulador de crescimento. Isso resultou, provavelmente, do atraso na emergência (Figura 1), uma vez que não houve variação significativa nas taxas de crescimento absoluto (TCA), com a variação na concentração de PBZ, entre o $15^{\circ}$ e $30^{\circ}$ dia após a semeadura (Tabela 1 e Figura 2). 
Tabela 1. Taxa de crescimento absoluto da altura (TCA), diâmetro do caulículo (DC) e área foliar de plântulas (AF), em função de métodos de aplicação (embebição de sementes e rega de mudas) e da concentração de paclobutrazol (PBZ), aos 30 dias após a semeadura, para tomateiro híbrido AF 7631. Ilha Solteira (SP), 2007.

\begin{tabular}{|c|c|c|c|c|c|}
\hline \multirow{2}{*}{$\begin{array}{c}\text { Concentração de } \\
\text { PBZ } \\
\left(\mathrm{mg} \mathrm{L}^{-1}\right)\end{array}$} & \multicolumn{2}{|c|}{$\begin{array}{c}\mathrm{TCA}^{(1)} \\
\left(\mathrm{mm} \mathrm{dia}^{-1}\right)\end{array}$} & \multirow[t]{2}{*}{$\begin{array}{l}\mathrm{DC} \\
(\mathrm{mm})\end{array}$} & \multicolumn{2}{|c|}{$\begin{array}{c}\mathrm{AF} \\
\left(\mathrm{cm}^{2} \text { plântula-1 }\right)\end{array}$} \\
\hline & Embebição & Rega & & Embebição & Rega \\
\hline 0 & $4,59 \mathrm{a}$ & $5,13 \mathrm{a}^{(\mathrm{RL})}$ & 2,77 & $31,82 \mathrm{a}^{(\mathrm{RQ})}$ & $31,50 \mathrm{a}^{(\mathrm{RL})}$ \\
\hline 50 & $3,70 \mathrm{a}$ & $2,06 \mathrm{~b}$ & 2,57 & $19,42 \mathrm{~b}$ & $26,71 \mathrm{a}$ \\
\hline 100 & $4,97 \mathrm{a}$ & $1,37 \mathrm{~b}$ & 2,74 & $27,76 \mathrm{a}$ & $22,16 \mathrm{~b}$ \\
\hline CV $(\%)$ & \multicolumn{2}{|c|}{-----------27,12----------- } & 5,92 & \multicolumn{2}{|c|}{------------5,28-------------- } \\
\hline
\end{tabular}

Médias seguidas pelas mesmas letras, nas linhas, para cada característica e período de avaliação, não diferem entre si pelo teste de Tukey $(\mathrm{p}>0,05)$

RL - Regressão linear significativa; RQ - Regressão quadrática significativa

(1) Taxa de crescimento absoluto entre o $15^{\circ}$ e $30^{\circ}$ após a semeadura.

Fonte: Elaboração dos autores.

Figura 2. Altura de plantas (A), taxa de crescimento absoluto (B), área foliar (C) e massa de matéria seca da parte aérea, do sistema radicular e total (D), em função de métodos de aplicação e de concentrações de paclobutrazol, para plântulas de tomateiro, híbrido AF 7631, aos 30 dias após a semeadura. Ilha Solteira (SP), 2007.
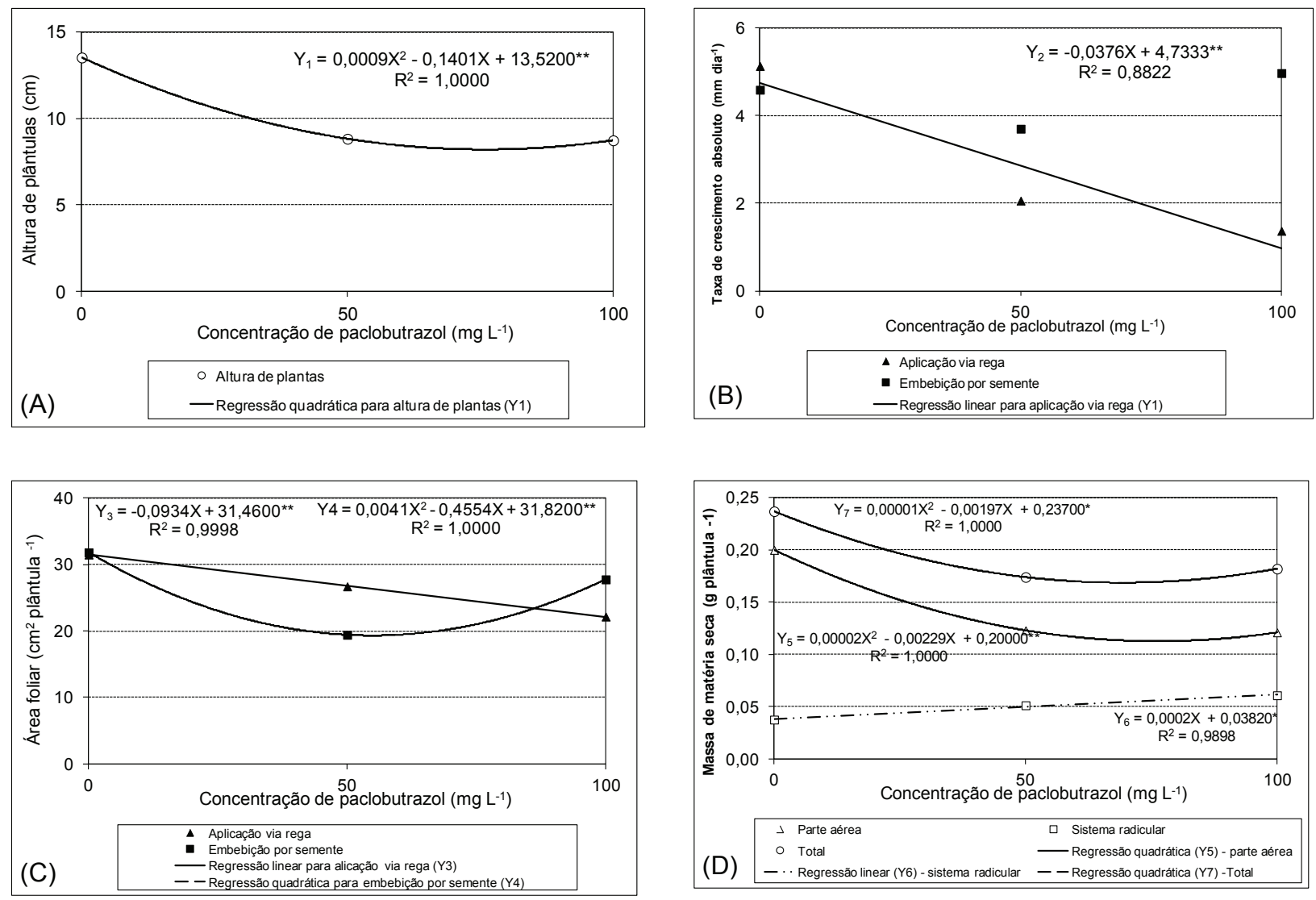

* - regressão polinomial significativa $(\mathrm{P}<0,05)$; ** - regressão polinomial significativa $(\mathrm{P}<0,01)$.

Fonte: Elaboração dos autores. 
Quando o PBZ foi aplicado via rega após 15 dias da semeadura, o aumento na concentração do regulador de crescimento, também, implicou em diminuição significativa da altura das plântulas, entretanto, neste caso, como conseqüência da redução linear da taxa de crescimento absoluto (Tabela 1 e Figura 2). Fisiologicamente, a redução na altura das plantas promovida pelo uso do PBZ está ligada à inibição da conversão de ent-caureno para ácido de ent-caurenóico, na biossíntese de GA, que resulta em redução nos níveis de todas as formas de ácidos giberélicos, determinando diminuição na taxa de elongação e divisão celular (FLETCHER et al., 2000). Silva e Faria Junior (2011) verificaram reduções na altura e na emissão de brotos laterais de plantas de tomateiro, em intensidades que variaram com as concentrações testadas.

O efeito do PBZ sobre a altura de plantas possibilitou a obtenção de plantas mais compactas e, portanto, menos frágeis, uma vez que, aliado à redução no porte das plântulas, não foram observados efeitos significativos do triazol sobre o diâmetro do caulículo, medido na altura do colo, aos 30 dias após a semeadura (Tabela 1).

No que se refere à área foliar de plântulas, houve interação significativa entre o método de aplicação e a concentração de PBZ (Tabela 1). Deste modo, na concentração de $50 \mathrm{mg} \mathrm{L}^{-1}$ de $\mathrm{PBZ}$, com a aplicação via rega foram obtidas plântulas com área foliar $\left(26,71 \mathrm{~cm}^{2}\right.$ plântula-1) superior ao tratamento por embebição de sementes $\left(19,42 \mathrm{~cm}^{2}\right.$ plântula-1), Tabela 1. Contrariamente, na maior concentração de PBZ, verificou-se que a maior aérea foliar $\left(27,76 \mathrm{~cm}^{2}\right.$ plântula $\left.{ }^{-1}\right)$ foi alcançada pelas plântulas originadas de sementes que foram embebidas com o triazol, com média significativamente superior àquela das plântulas que receberam o produto via rega $\left(22,16 \mathrm{~cm}^{2}\right.$ plântula-1 $)$.

Ainda, enquanto na aplicação via rega houve uma diminuição linear da área foliar, com o aumento da concentração do regulador de crescimento, nos tratamentos com embebição das sementes, a variação da área foliar se ajustou a uma regressão quadrática, com valor mínimo estimado para concentração de $55 \mathrm{mg} \mathrm{L}^{-1}$ (Figura 2C).

Os métodos de aplicação do PBZ não se distinguiram quanto ao acúmulo de matéria seca de parte aérea e total, porém, com a aplicação do produto via rega foram obtidas mudas com massa de matéria seca de raiz significativamente superior àquela de plântulas oriundas de sementes tratadas por embebição (Tabela 2). Também, foi observado que o aumento na concentração de PBZ, independentemente do método de aplicação empregado, determinou variações nas massas de matéria seca da parte aérea e total, conforme um ajuste quadrático (Tabela 2 e Figura 2D), com valores mínimos, respectivamente, para as concentrações do triazol de 76 e $71 \mathrm{mg} \mathrm{L}^{-1}$. Por outro lado, a massa de matéria seca de raiz aumentou linearmente com o incremento na concentração de PBZ (Tabela 2 e Figura 2D), com um acúmulo de matéria seca das raízes, para a concentração de $100 \mathrm{mg} \mathrm{L}^{-1}$, cerca de $62 \%$ superior à testemunha.

Esses resultados são promissores, pois, como discutido por Latimer (1991), mudas mais compactas e com bom enraizamento são desejáveis, pois apresentam maior resistência aos estresses ambientais e a algumas doenças, por ocasião do transplantio para o campo.

Segundo relatado por Hamid e Williams (1997) e por Heuvel et al. 2000, plantas tratadas com paclobutrazol apresentaram folhas com coloração verde mais intensa, ocorrência, também, observada no presente ensaio, o que estaria relacionado ao aumento na síntese de clorofila e, indiretamente, ao aumento em sua concentração decorrente da redução do tamanho das células, resultando em aumento da eficiência fotossintética (DAVIS; STEFFENS; SANKHLA, 1988; BEROVA; ZLATEV, 2000). Todavia, não foi constatada, como esperado, redução na razão de área foliar (RAF) de plantas tratadas com PBZ, em relação à testemunha (Tabela 2), tendo sido necessários, em média, $137 \mathrm{~cm}^{2}$ de área foliar para produzir um grama de matéria seca. 
Tabela 2. Médias de massa de matéria seca da parte aérea (MSA), massa de matéria seca de raízes (MSR), massa de matéria seca total (MST), e razão de área foliar (RAF), aos 30 dias após a semeadura, para mudas de tomateiro, híbrido AF 7631, em função de métodos de aplicação de paclobutrazol. Ilha Solteira (SP), 2007.

\begin{tabular}{|c|c|c|c|c|}
\hline & MSA & MSR & MST & RAF \\
\hline & \multicolumn{3}{|c|}{ 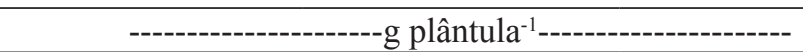 } & $\mathrm{cm}^{2} \mathrm{~g}^{-1}$ \\
\hline \multicolumn{5}{|c|}{ Método de aplicação } \\
\hline Embebição de.semente & $0,154 \mathrm{a}$ & $0,031 \mathrm{~b}$ & $0,185 \mathrm{a}$ & $144,60 \mathrm{a}$ \\
\hline Rega de mudas & $0,142 \mathrm{a}$ & 0,069 a & $0,210 \mathrm{a}$ & $130,10 \mathrm{a}$ \\
\hline CV(\%) & 17,90 & 46,14 & 16,87 & 16,60 \\
\hline
\end{tabular}

Médias seguidas pela mesma letra, nas colunas, em cada característica estudada, não diferem entre si pelo teste de Tukey $(\mathrm{P}>0,05)$. Fonte: Elaboração dos autores.

\section{Conclusões}

A aplicação de paclobutrazol via rega de plântulas, aos 15 dias após a semeadura, não comprometeu a emergência de plântulas, reduziu significativamente a taxa de crescimento das plântulas e, conseqüentemente, o porte das mudas, sem afetar o diâmetro do caulículo, além de permitir acúmulo de matéria seca de raízes.

Aconcentração de $50 \mathrm{mg} \mathrm{L}^{-1}$ mostrou-se suficiente para obtenção de plântulas mais compactas, sem prejuízo à área foliar, na aplicação via rega, além de permitir um incremento de cerca de $37 \%$ na massa de matéria seca de raízes.

\section{Agradecimentos}

À CAPES, pela concessão de bolsas de doutorado, e à Sakata Seed Sudamerica, pelo fornecimento das sementes.

\section{Referências}

ANDRIOLO, J. L.; BOEMO, M. P.; BONINI, J. V. Crescimento e desenvolvimento de mudas de tomateiro e melão empregando os métodos de irrigação por microaspersão, inundação subsuperficial e flutuação. Horticultura Brasileira, Brasília, v. 19, n. 3, p. 332-345, 2001 .

BANINASAB, B.; GHOBADI, C. Influence of paclobutrazol and application methods on hightemperature stress injury in cucumber seedlings. Journal of Plant Growth Regulation, Nova Iorque, v. 30, n. 2, p. 213-219, 2011.
BARBOSA, R. M.; COSTA, D. S.; SÁ, M. E. Envelhecimento acelerado de sementes de espécies oleráceas. Pesquisa Agropecuária Tropical, Goiânia, v. 41, n. 3, p. 328-335, 2011.

BENINCASA, M. M. P. Análise de crescimento de plantas: noções básicas, Jaboticabal: FCAV-UNESP, 1988. $41 \mathrm{p}$.

BEROVA, M.; ZLATEV, Z. Physiological response and yield of paclobutrazol treated tomato plants (Lycopersicon esculentum Mill.). Plant Growth Regulation, Dordrecht, v. 30, n. 2, p. 117-123, 2000.

BOVI, J. E.; MINAMI, K. Condicionamentos mecânicos de mudas de tomateiro (Lycopersicon esculentum Mill.). Scientia Agricola, Piracicaba, v. 56, n. 1, p. 97-101, 1999.

DAVIS, T. D.; STEFFENS, G. L.; SANKHLA, N. Triazole plant growth regulators. Horticultural Reviews, New York, v. 10, n. 1, p. 63-105, 1988.

FLETCHER, R. A.; GILlEY, A.; SANKHLA, N.; DAVIS, T. Triazoles as plant growth regulators and stress protectants. Horticultural reviews, New York, v. 24, n.1, p. 55-138, 2000.

GIOVINAZZO, R.; SOUZA-MACHADO, V. Paclobutrazol responses with processing tomato in France. Acta horticulturae, The Hague, n. 542, p. 355358, 2001.

HAJIHASHEMI, S.; KIAROSTAMI, K.; SABOORA, A.; ENTESHARI, S. Exogenously applied paclobutrazol modulates growth in salt-stress wheat plants. Plant Growth Regulation, Dordrecht, v. 53, n. 2, p. 117-128, 2007.

HAMID, M. M.; WILLIAMS, R. R. Effect of different types and concentrations of plant growth retardants on Sturt's desert pea (Swainsona formosa). Scientia Horticulturae, Amsterdam, v. 71, n. 1, p. 79-85, 1997. 
HEUVEL, K. J. P. T. van den; HEIJNEN, P. H. F.; BARENDSE, G. W. M.; WULLEMS, G. J. Expression of two gibberellin-regulated cDNAs during early flower development in tomato (Solanum lycopersicon). Effect of grafting and paclobutrazol. Physiologia Plantarum, Copenhagen, v. 108, n. 1, p. 95-100, 2000. Disponível em: $<$ http://www.blackwellynergy.com/action/showPdf?su bmitPDF $=$ Full + Text + PDF $+\% 28166+K B \% 29 \&$ doi $=10$ .1034\%2Fj.1399-3054.2000.108001095.x\&cookieSet =1>. Acesso em: 02 out. 2007.

HUNG, P. E.; FRITZ, V. A.; WATERS, L. Infusion of shrunken-2 sweet corn seed with organic solvents: effects on germination and vigor. Hortscience, Alexandria, v. 27, n. 5, p. 467-470, 1992.

KENDE, H.; ZEEVAART, J. A. D. The five "classical" plant hormones. The Plant Cell, Rockville, v. 9, n. 7, p. 1197-1210, 1997.

LATIMER, J. G. Mechanical conditioning for control of growth and quality of vegetable transplants. HortScience, Alexandria, v. 26, n. 12, p. 1456-1461, 1991.

MÄGE, F.; POWELL, L. Inhibition of stratification and germination of apple seeds by paclobutrazol. HortScience, Alexandria, v. 25, n. 5, p. 577-577, 1990.

MAGUIRRE, J. D. Speed of germination aid in selection and evaluation for seedling and vigour. Crop Science, Madison, v. 2, n. 2, p. 176-177, 1962.

NASCIMENTO, W. M.; SALVALAGIO, R.; SILVA, J. B. C. Condicionamento químico do crescimento de mudas de tomate. Horticultura Brasileira, Brasília, v. 21, n. 2, p. 1-3, jul. 2003. Suplemento.

NICOLA, S.; BASOCU, L. Overhead, ebb and flow, and floatation: analysis of three irrigation systems to grow lettuce transplants. In: INTERNATIONAL SYMPHOSIUM ON PROTECTED CULTIVATION IN MILD WINTER CLIMATES: CURRENT TRENDS FOR SUSTAINABLE TECHNOLOGIES, 1., 2000, Cartagena. Abstracts... Cartagena: Ishs, 2000, p. 143.

PASIAN, C. C.; BENNETT, M. Paclobutrazol soaked marigold, geranium, and tomato seeds produce short seedlings. HortScience, Alexandria, v. 36, n. 4, p. 721731, 2001.
PILL, W. G.; GUNTER, J. A. Emergence and shoot growth of cosmos and marigold from paclobutrazoltreated seed. Journal of Environmental Horticulture, Washington, v. 19, n. 1, p. 11-14, 2001.

RADEMACHER, W. Growth retardants: effects on gibberellin biosynthesis and other metabolic pathways. Annual Review of Plant Physiology and Plant Molecular, Palo Alto, v. 51, p. 501-531, 2000.

SELEGUINI, A.; FARIA JÚNIOR, M. J. A.; SENO, S.; SANTOS, J. I.; SILVA, K. S. S.; LEMOS, O. L. Vida útil e qualidade de frutos de tomateiros tratados com paclobutrazol. Revista Ceres, Viçosa. v. 58, n. 4, p. 470475, 2011.

SHARMA, D. K.; DUBEY, A. K.; SRIVASTAV, M.; SINGH, A. K.; SAIRAM, R. K.; PANDEY, R. N.; DAHUJA, A.; KAUR, C. Effect of putrescine and paclobutrazol on growth, physiochemical parameters, and nutrient acquisition of salt-sensitive citrus rootstock Karna khatta (Citrus karna Raf.) under $\mathrm{NaCl}$ stress. Journal of Plant Growth Regulation, New York, v. 30, n. 3, p. 301-311, 2011.

SILVA, K. S.; FARIA JÚNIOR, M. J. A. Uso de paclobutrazol como estratégia para redução do porte e da brotação lateral de plantas de tomateiro. Ciência e Agrotecnologia, Lavras, v. 35, n. 3, p. 539-546, 2011.

STILL, J. R.; PILL, W. G. Growth and stress tolerance of tomato seedlings (Lycopersicon esculentum Mill.) in response to seed treatment with paclobutrazol. Journal of Horticultural Science \& Biotechnology, Ashford, v. 79, n. 2, p. 197-203, 2004.

SYMONS, P. R. R. Paclobutrazol: its application and effect on aspects of plant morphology, anatomy, biochemistry and physiology. Pietermaritzburg, Department of Horticultural Science, University of Natal. 1989. 82 p. 
